\title{
Microstructure and mechanical properties of sintered (2-4)Mn-(0.6-0.8)C steels
}

\author{
A. Cias, S. C. Mitchell, A. Watts, and A. S. Wronski
}

\begin{abstract}
Mechanical properties of 2-4\% manganese PM steels were determined in tension and in bending following laboratory sintering in dry, hydrogen rich atmospheres. Young's modulus determined by an extensometric technique was about $115 \mathrm{GPa}$; when measured by an ultrasonic method it was about $153 \mathrm{GPa}$, in accordance with the 'law of mixtures'. The microstructures, significantly devoid of oxide networks, were predominantly pearlitic, but frequently with variability for specimens similarly processed, resulting in appreciable variations in the stresses for macroscopic yielding and fracture. The majority of the experiments were conducted on 3 and $4 \mathrm{Mn}-$ $0.6 \mathrm{C}$ alloys and for these $R_{0.1}$ was in the range 275-500 MPa, tensile strength (TS) 300-600 MPa, and (apparent) transverse rupture strength (TRS) 640-1260 MPa. Statistical techniques were employed to analyse the data. When careful control of processing was maintained, the Weibull modulus was highest, at about 17 , for TS of furnace cooled specimens, and lowest, about 6 , for TRS of the rapidly cooled specimens. In order to interpret the significant differences between the TRS and the TS values, both apparently measuring the critical stress for cracking after strains of up to $7 \%$, a two stage normalising technique for TRS was adopted. By taking account of the plastic strains preceding failure, the elastic 'strength of materials' formula was modified to allow true fracture stresses to be calculated. It was also postulated that failure was initiated from a population of flaws of variable size and then the 'normalised' bend strengths, smaller than TRSs, were shown to correspond well with TSs. It is suggested that this combined plasticity correction and Weibull analysis approach, which has a sound scientific basis, should be employed to interpret bend test data in preference to empirical correlations between TS and TRS.
\end{abstract}

$\mathrm{PM} / 0812$

Dr A. Cias is in the Powder Metallurgy Department, Academy of Mining and Metallurgy, AGH, Al. Mickiewicza 30, 30-059 Krakow, Poland, and Mr S. C. Mitchell, Mr A. Watts, and Professor A. S. Wronski are with the Engineering Materials Group, Department of Mechanical and Medical Engineering, University of Bradford, Bradford, West Yorks. BD7 1DP, UK. Manuscript received 27 August 1998; accepted 11 March 1999.

(C) 1999 IoM Communications Ltd.

\section{INTRODUCTION}

\section{PM manganese alloys}

Recent commercial developments in PM concerning higher strength and toughness, and fatigue and wear resistance, are mainly achieved through additions of expensive alloying elements, such as nickel and molybdenum, to the baseline $\mathrm{Fe}-\mathrm{C}-\mathrm{Cu}$ system. Manganese is an excellent substitute for nickel, as $\mathrm{Fe}-\mathrm{Mn}-\mathrm{C}$ alloys have excellent hardenability and manganese is much cheaper. In particular, when combined with chromium or molybdenum, this alloy system has the potential for utilising lower bainitic structures to optimise mechanical and tribological properties without the need for a separate post-sintering heat treatment. Further important reasons for nickel substitution are the carcinogenic and allergenic properties of nickel powders and their attendant health and safety directives (see, for example, Ref. 1).

A number of previous attempts to develop manganese steels have been reported, ${ }^{2-6}$ but commercial exploitation appears restricted to $<1.5 \% \mathrm{Mn}$ alloys. ${ }^{7}$ It is postulated that the problems of successful PM exploitation of richer manganese alloys are associated with the formation of oxide networks (Fig. 1) present in such experimental alloys. In a European Union Copernicus project, ${ }^{8}$ probably for the first time, 3 and $4 \% \mathrm{Mn}$ steels free of oxide networks have been sintered, and prototype gears for a hand power tool and a concrete mixer were manufactured. The laboratory processing data are presented below; a preliminary report on sintering mechanisms has already been made. ${ }^{8}$ The project naturally involved examination of the microstructure, microcomposition, and mechanical properties of these alloys, and is the subject of the present paper.

\section{Mechanical properties of sintered alloys}

Mechanical properties standards exist to sample the stiffness, strength, ductility, toughness, etc. of a batch of material to assess its fitness for purpose and the reproducibility of the property being measured. Like most metals standards, these were first developed for wrought or cast, i.e. fully dense, materials. Application of the same approach to sintered porous metals is necessary for design, quality control, commercial, and legal reasons. Unfortunately, when determining material parameters amenable to scientific interpretation, results of such standard tests have significant limitations. Properties of the metal itself are not sampled, but of a 'metal/air composite', which does not conform to the 'law of mixtures'. Further complications are present in interpretation if the sintered material possesses macroscopic, though limited, ductility and fails (by cracking) before the point of tensile instability is reached.

The problem starts with the value of Young's modulus $E$ as analysed by, for example, Moon. ${ }^{9}$ Where identical $E$ values are determined by both extensometric and ultrasonic methods for fully dense (including sintered) materials, ultrasonic methods give higher values for porous materials, ${ }^{9}$ because they relate to smaller strains. The reason for this is as well known as it is ignored: as plastic deformation in different sinter necks of a (standard) specimen starts at different loads, the plastic strain response is significant before the yield stress (however defined) is reached. A physical approach is that $E$ is a property of the metal itself, the same whether the test specimen is porous or not: it is a genuine material constant. The extensometric test on a porous specimen, however, measures the stress-strain response of a 


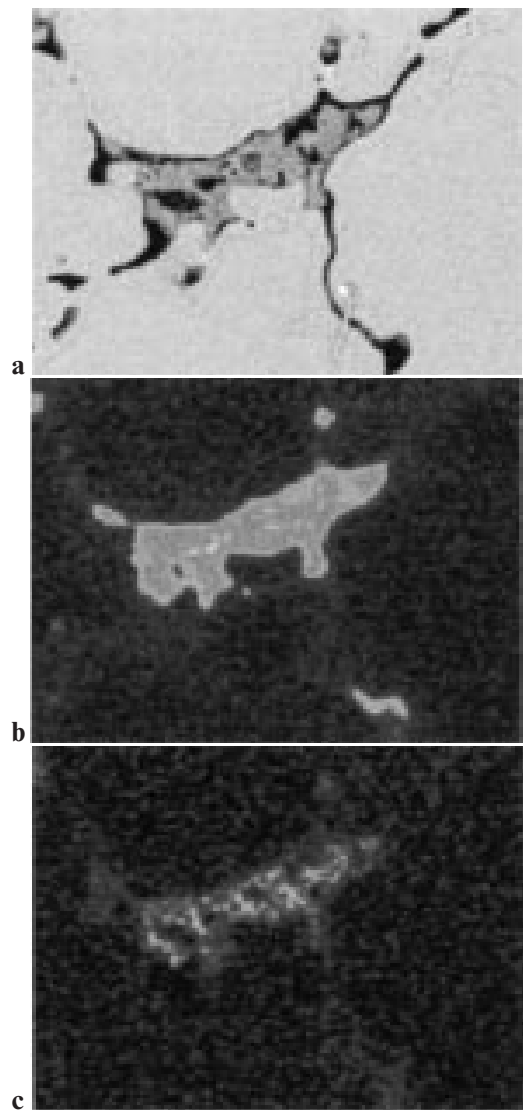

$a$ SEM image; $b$ Mn X-ray dot map; $c$ O X-ray dot map

1 Typical oxide networks in $3 \% \mathrm{Mn}$ steel sintered at $1120^{\circ} \mathrm{C}$ in $75 \mathrm{H}_{2}-25 \mathrm{~N}_{2}$ atmosphere with poor dewpoint

metal/air composite, for which Hookean behaviour ceases at significantly smaller stresses than in dense specimens.

Extensive misunderstanding has developed regarding the relationship between the bend and tensile strengths of sintered materials tested in standard ways, with conversion ratios being proposed. ${ }^{10,11}$ The first point to make concerns the strength of materials formula for three point bending, invariably used to calculate the transverse rupture strength

$$
\mathrm{TRS}=\frac{3 F l}{2 b t^{2}}
$$

where $F$ is the maximum load, $b$ the specimen width, $t$ its depth, and $l$ the span. It is valid only for linear elastic material behaviour, which is generally the case for ceramics. Fortunately most metallic materials possess macroscopic plasticity, which renders the 'elastic' formulae inapplicable. ${ }^{12}$ Straffelini et al. ${ }^{13}$ have further pointed out that in sintered materials, the differences in the deformation behaviour in tension and compression lead to a shift of the beam neutral axis. Even at relatively small strains, when this shift can be neglected, correct analysis requires input of values of Young's modulus, yield stress, and work hardening rate. ${ }^{12}$ As this necessitates use of sensitive instrumentation and of formulae not as simple as equation (1), such a procedure has not been adopted.

The next point to make concerns the relationship between bend and tensile strengths. Naively one might anticipate that these are equal for any material, since both refer to a tensile mechanism of failure. The reasons that the recorded values are generally different depend on the material and sensitivity of detecting non-linear loaddeflection response in a mechanical properties test. First consider the case of a fully dense brittle material, i.e. when the response is linear (whatever the sensitivity), failing by cracking from inherent flaws. As these defects do not have the same size, shape, and orientation, strengths determined on identical specimens have a scatter depending on the distribution of these failure initiating flaws and especially their variation in size. If the material possesses a constant resistance to the propagation of these defects (fracture toughness), the problem can be treated statistically. The 'weakest link' Weibull ${ }^{14}$ analysis has been adopted almost universally for the analysis of brittle fracture of ceramics. It postulates that the worst combination of the size of the flaw and the magnitude of the tensile stress there applied, determines the strength of the specimen.

Consider now brittle tensile and bend specimens of identical material and volume. In a loaded tensile testpiece, the entire gauge volume is subjected to the same (maximum) stress. Only half the three point bend specimen is subjected to a tensile stress, and in that portion the stress varies from maximum to zero, traversing from tensile surface midspan to the neutral axis and to the span extremities. Thus, strengths of bend specimens will generally be higher than those of the tensile specimens, since it is unlikely that the largest flaw will be where the maximum stress is applied in a specimen undergoing simple or pure bending. Quite sophisticated analyses, which take account of specimen size, shape, and mode of loading, have been developed for ceramic materials. ${ }^{15}$ If the distribution of flaws is the same in tensile and bend specimens, however, and if the same type of flaw is responsible for brittle fracture in the material of whatever shape and size, a simple two parameter Weibull analysis $^{16,17}$ should apply. Depending on the scatter, quantified by the Weibull modulus $m$, and the volumes (or areas) of the bend and tensile specimens, the relationship between the true bend strength $\sigma_{\max }$ and the tensile strength TS has been shown to be ${ }^{17}$

$$
\frac{\sigma_{\max }}{\mathrm{TS}}=\left[\frac{2 L W T(m+1)^{2}}{l w t}\right]^{1 / \mathrm{m}}=\left[2(m+1)^{2}\right]^{1 / \mathrm{m}}
$$

when the tensile gauge length $L$ is equal to $l$, the span in the three point bend test, and the specimen widths $W$ and $w$ are equal, as are the tensile specimen thickness $T$ and the depth $t$ of the beam, to give specimens of equal test volume.

Unfortunately the applicability of this Weibull formula to standard specimens of metallic PM materials is limited by the plasticity of the specimens and differences in density and microstructure (frequently present) between the two types of test specimen. To take account of the plasticity requires its quantification, and therefore precise experimentation to determine the true fracture strengths of bend specimens. Analysis of the data presented in the present paper attempts to deal with the aforementioned problems.

\section{EXPERIMENTAL PROCEDURES \\ Processing}

Höganäs sponge, NC100.24, and water atomised $\mathrm{ABC} 100.30$ iron powders were used for this investigation. Carbon was introduced as fine graphite and manganese as ferromanganese from two different sources: Elkem and Huta Pokoj. The Elkem powder was a byproduct (fines from electrode production) of composition $\mathrm{Fe}-79 \cdot 3 \mathrm{Mn}-$ $1 \cdot 2 \mathrm{C}-0 \cdot 4 \mathrm{Si}-2 \cdot 3 \mathrm{O}-0 \cdot 1 \mathrm{~N}$, sieved to less than $40 \mu \mathrm{m}$. The Huta Pokoj HP3 (Fe-79.0Mn-6.4C-0.7Si-0.1O-0.01N) fine particles had to be milled under nitrogen before sieving. Eventual compositions of the sintered compacts were not significantly influenced by the powder source. Alloys with manganese in the range $2-4 \%$ and carbon contents between 0.4 and $0.8 \%$ were investigated.

Mixing and die compaction (typically at $600 \mathrm{MPa}$ ) were followed by sintering in a hydrogen or hydrogen rich atmosphere in the temperature range $1120-1300^{\circ} \mathrm{C}$, with careful control of both inlet dewpoint and gas flowrate. 


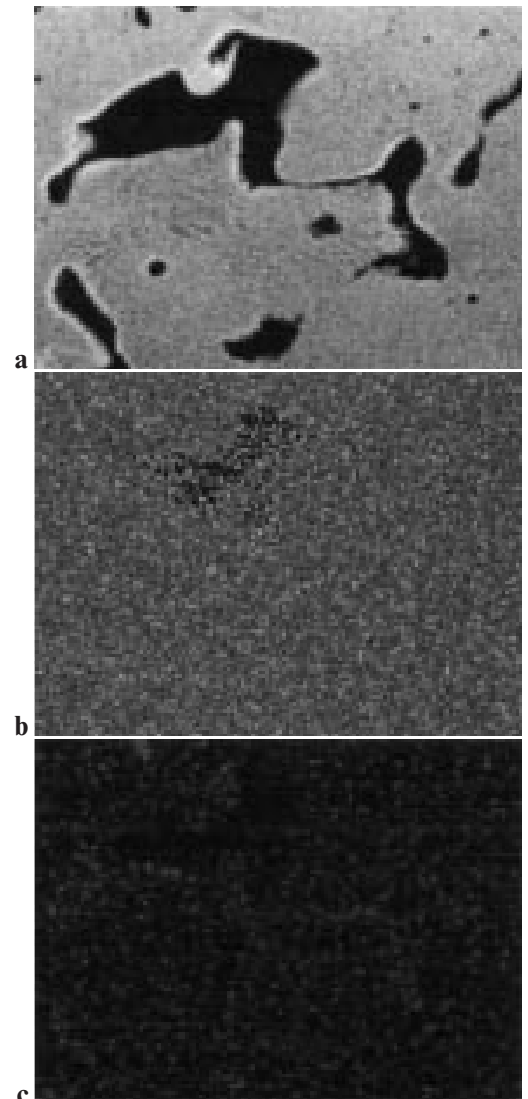

$a$ SEM image; $b$ Mn X-ray dot map; $c$ O X-ray dot map

2 Images of $3 \% \mathrm{Mn}$ steel sintered at $1120^{\circ} \mathrm{C}$ in $75 \mathrm{H}_{2}-25 \mathrm{~N}_{2}$ atmosphere with dewpoint $<-60^{\circ} \mathrm{C}$

Temperatures for successful laboratory processing were generally in excess of $1180^{\circ} \mathrm{C}$ for dewpoints in the range -40 to $-60^{\circ} \mathrm{C}$. These are thus industrially attainable using modern gas drying equipment. Additionally both theoretical thermodynamic ${ }^{18}$ and experimental indications are that poorer dewpoints and temperatures $<1140^{\circ} \mathrm{C}$ can be tolerated if getter powder systems and semiclosed containers are employed. ${ }^{8}$ Cooling rates in several laboratory furnaces and an industrial link belt furnace (ZMT, Trzebinia, Poland) ranged from 3 to $40 \mathrm{~K} \mathrm{~min}^{-1}$. Dimensional changes on sintering were generally less than $1 \%$ (Refs. 8 and 19) and densities were in the range $6 \cdot 7-7 \cdot 0 \mathrm{~g} \mathrm{~cm}^{-3}$.

\section{Metallographic and microstructural examinations}

Conventional metallographic techniques were supplemented by scanning electron microscopy, generally on a Jeol 6400 fitted with a Kevex Sigma 3 energy dispersive $\mathrm{X}$-ray microanalysis system which enabled fairly accurate determinations of microcomposition, in particular of local manganese concentrations.

\section{Tensile and bend testing}

Standard ISO tensile and transverse rupture specimens were tested on mechanical and servohydraulic industrial machines at extension rates of $0.5 \mathrm{~mm} \mathrm{~min}^{-1}$, in some instances involving extensometric measurements. Young's modulus was also determined using an ultrasonic technique. Fracture strains were in the range $0 \cdot 3-7 \cdot 5 \%$, necessitating a plasticity correction for the TRS specimens.

\section{RESULTS}

\section{Metallographic and microstructural observations}

The most striking feature of the microstructure with dewpoint $<-60^{\circ} \mathrm{C}$ was the absence of oxide networks

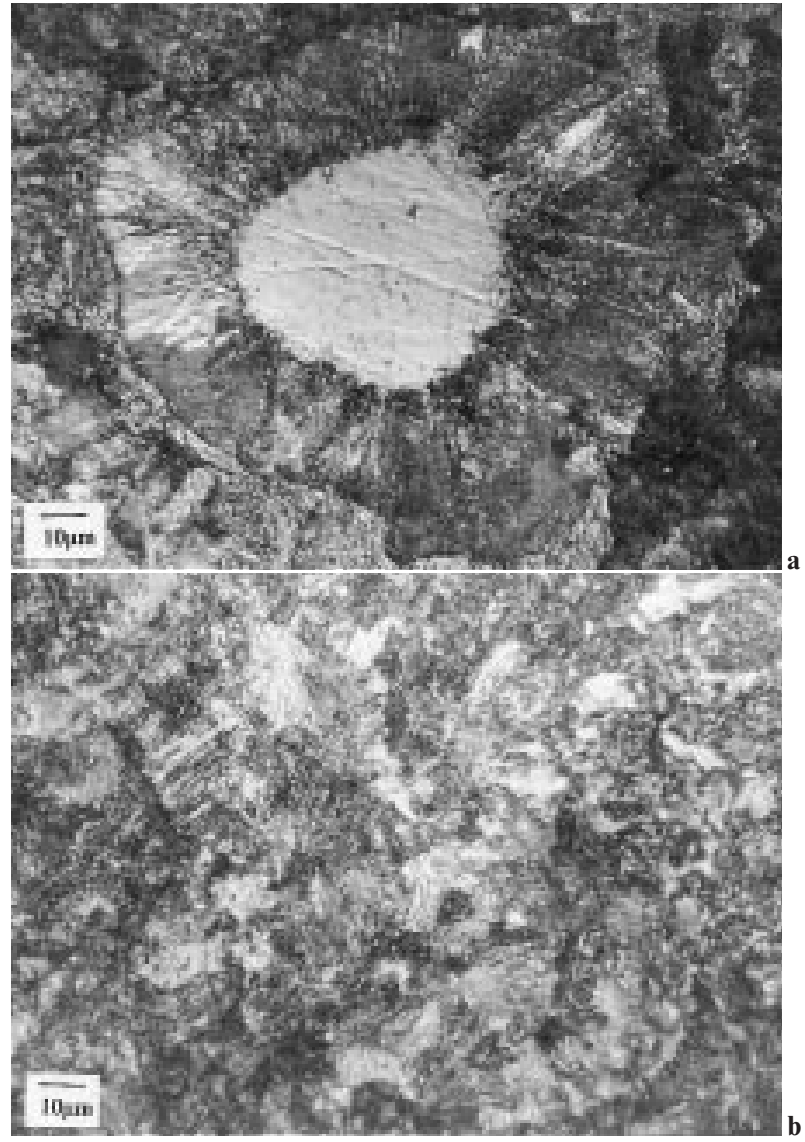

$a \mathrm{ABC} 100.30$ water atomised $\mathrm{Fe} ; b \mathrm{NC} 100.24$ sponge $\mathrm{Fe}$

3 Microstructures of $3 \mathrm{Mn}-\mathbf{0} \cdot \mathbf{8 C}$ steels sintered using given powders and furnace cooled at $3 \mathrm{~K} \mathrm{~min}-1$

(Fig. 2), hitherto characteristic of PM manganese steels, ${ }^{4-8}$ an example of which is presented in Fig. 1. Comparing the $\mathrm{X}$-ray dot maps, it is evident that, owing to poor dewpoint control, there is association of oxygen and manganese (Fig. $1 b$ and $c$ ), and, to a lesser extent, iron, whereas in specimens correctly processed during the present investigation, oxygen is hardly detectable (Fig. 2). All microstructures, even of the predominantly pearlitic furnace cooled specimens (Fig. 3) were complex and inhomogeneous and additionally comprised ferrite (white with grain boundaries) and retained austenite. For the specimens cooled at $40 \mathrm{~K} \mathrm{~min}^{-1}$ (Fig. 4), very fine pearlite (dark), ultrafine pearlite, troostite (black), bainite (a product of diffusional transformation), and martensite were also detected. ${ }^{8}$ Areas of high manganese retained austenite were present around larger pores owing to the transport of manganese in the vapour phase and this was evident even in the slow cooled condition. It can be seen that the specimens made from $\mathrm{ABC} 100.30$ water atomised powder show larger, more rounded ferrite cores than those made using NC100.24 sponge iron powder (Fig. 3). This is attributable to the manganese diffusion distance being of the order of $15 \mu \mathrm{m}$ at sintering temperatures $<1150^{\circ} \mathrm{C}$ and times of about $1 \mathrm{~h}^{18}$ Owing to the sponge nature of the NC100.24, manganese vapour is able to reach both the inside and outside surfaces of the iron powder particles, thus achieving greater homogeneity.

\section{Mechanical properties}

Over 300 specimens were tested in tension or simple bending during the research and development programme. ${ }^{8}$ A number of determinations of the Young's modulus were made using instrumented standard ISO tensile tests at an 


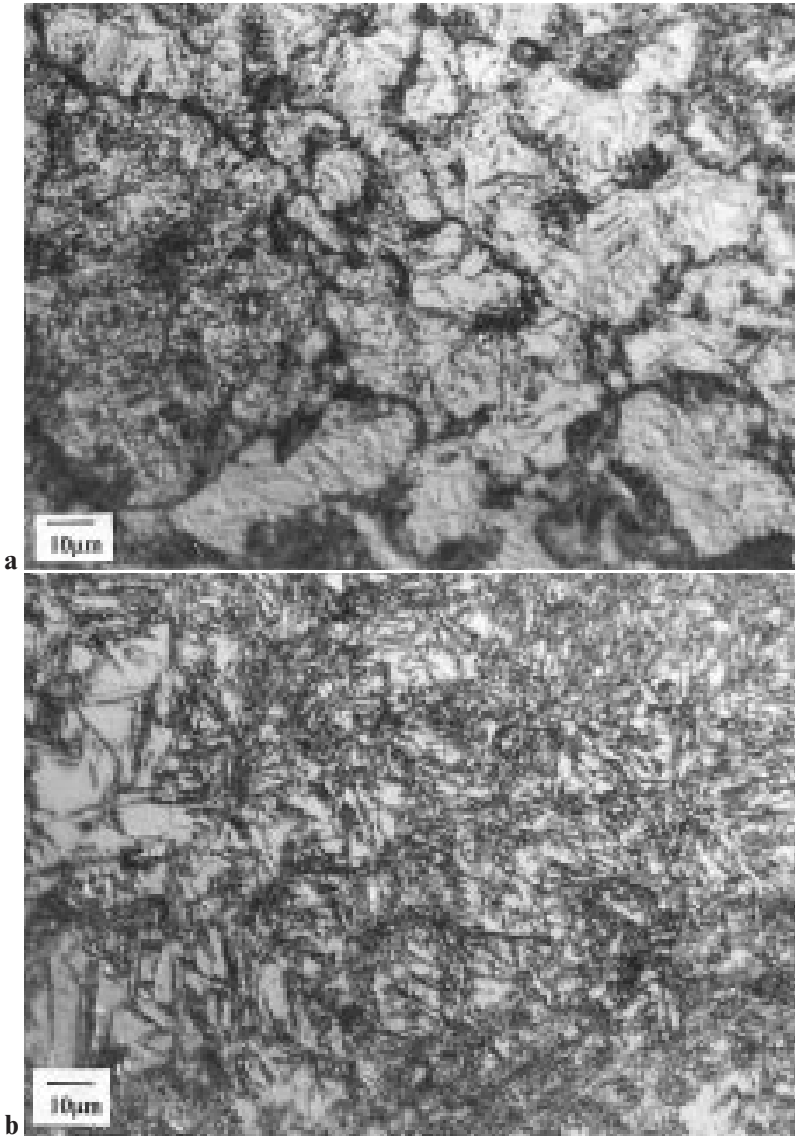

a $\mathrm{ABC} 100.30$ water atomised $\mathrm{Fe}$ showing inhomogeneous mixed structure of bainite, martensite and retained austenite; $b$ NC100.24 sponge Fe showing mainly martensite with some retained austenite

4 Microstructures of $3 \mathrm{Mn}-0 \cdot 8 \mathrm{C}$ steels sintered using given powders and convectively cooled at $40 \mathrm{~K} \mathrm{~min}^{-1}$

extension rate of $0 \cdot 1 \mathrm{~mm} \mathrm{~min}^{-1}$ and conventional ultrasonic techniques. The former testing method gave results in the range $110-120 \mathrm{GPa}$ and the latter $146-160 \mathrm{GPa}$ (i.e. approaching the law of mixtures value), in accord with published data for sintered steels. ${ }^{9,11,20}$ As the object of the present project was the attainment of strengths specified in ISO 5753-3: P3084 and P3085 for Ni-Cu-Mo steels, data for tensile strengths $<330 \mathrm{MPa}$ will not be assessed. Suffice to report that batches of $3 \mathrm{Mn}-0 \cdot 6 \mathrm{C}$ alloy ISO tensile specimens sintered in a conventional industrial link belt furnace in open trays at $1140^{\circ} \mathrm{C}$, with no subsequent heat treatment, had fairly reproducible $(m=10)$ tensile strengths averaging 240-270 MPa. Densities were in the range $6 \cdot 6-6 \cdot 7 \mathrm{~g} \mathrm{~cm}^{-3}$.

Laboratory sintering of leaner, $2 \mathrm{Mn}-0.5 \mathrm{C}$ sponge iron tensile specimens at $1140^{\circ} \mathrm{C}$, with the slow cooling rate of $3 \mathrm{~K} \mathrm{~min}^{-1}$, produced densities of only $6 \cdot 4-6.5 \mathrm{~g} \mathrm{~cm}^{-3}$. These specimens had somewhat higher (290-380 MPa) and more reproducible Weibull $(m=17)$ tensile strength values (Fig. 5), i.e. approximating to P3084. Dogbone specimens of the same batch were also tested in simple bending with depth and span of 6.37 and $25 \mathrm{~mm}$ respectively. Using a component measuring machine to determine the radius of curvature of broken specimen pieces, plasticity was estimated to be typically in the range $0 \cdot 8-1 \cdot 5 \%$. The use of the TRS formula, therefore, somewhat overestimates the applied maximum tensile stress. The apparent bend strengths were in the range $570-770 \mathrm{MPa}$, but showed more scatter $(m \approx 10)$. There were indications that more than one failure mechanism was operating, rendering the

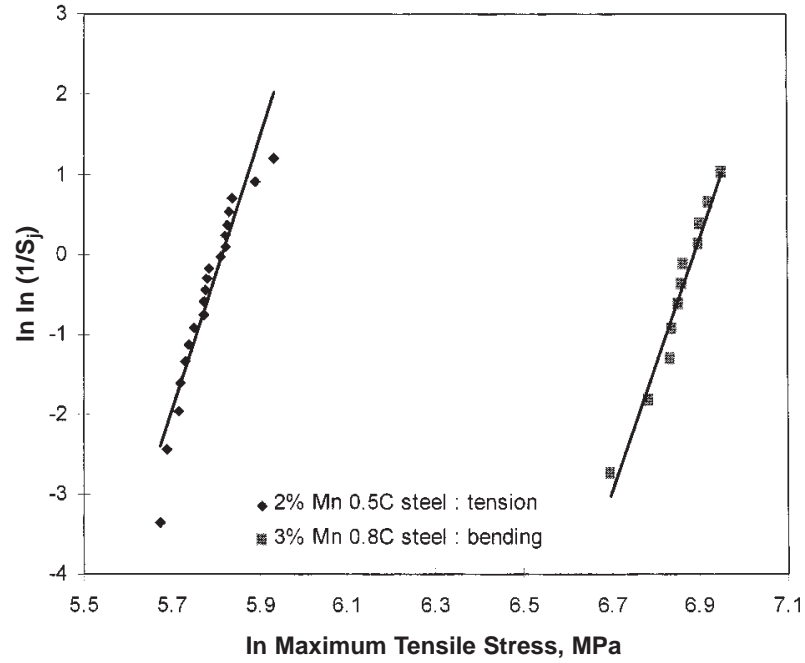

5 Weibull plots of maximum tensile stresses of furnace cooled specimens: $S_{\mathrm{i}}$ is survival probability

two parameter Weibull analysis inapplicable. This behaviour is thought to be related to the carbon segregation in this batch of dogbone specimens, which was evident as a banded/layered structure. It would appear that failures originated from the worst category of defect in the specimens tested in tension, but in bending the highest tensile stresses were not necessarily associated with this category of defect.

A number of alloys were screened for a promising combination of strength and ductility: 3 and $4 \% \mathrm{Mn}$, up to $0.8 \% \mathrm{C}$, and $\mathrm{Si}$ contents up to $0.55 \%$ were investigated. ${ }^{8}$ Recorded apparent bend strengths were in the range 600-1180 MPa and tensile strengths $260-520 \mathrm{MPa}$. No systematic correlations were possible, though there were indications that low strengths tended to be associated with high oxygen contents, emanating from the ferromanganese. In this set of experiments, the highest recorded strengths were for a low silicon $3 \mathrm{Mn}-0 \cdot 8 \mathrm{C}$ alloy. For the final part of the programme, it was accordingly decided to prepare low silicon, low oxygen, 3 and $4 \mathrm{Mn}-0 \cdot 8 \mathrm{C}$ steels. The remaining part of this report will concentrate on this group of alloys, furnace and convectively cooled.

There was a significant increase in apparent hardness as a result of relatively rapid convective cooling at $40 \mathrm{~K} \mathrm{~min}^{-1}$, compared with furnace cooling. At the surface, hardness increased from 120-170 to 160-390 HV10; the corresponding increase in apparent cross-section hardness was from $130-160$ to $160-290$. When all other compositional and processing parameters were the same, $4 \% \mathrm{Mn}$ alloys were harder than the $3 \%$ ones, sometimes by in excess of $100 \mathrm{HV} 10$. Except for a brittle group of $4 \mathrm{Mn}-0 \cdot 8 \mathrm{C}$ specimens, $R_{0.1}, R_{0.2}$, and $R_{\mathrm{m}}$ were in the ranges $275-500$, 295-580, and 300-600 MPa respectively for tensile tests on all $\mathrm{Fe}-\mathrm{Mn}-\mathrm{C}$ specimens. The effects of increased cooling rate and increasing manganese content were to lower the tensile strengths (Fig. 6), the reverse of the effect on the yield strengths. The effect of using different types of ferromanganese particles, in laboratory processing conditions, was not significant. Tensile plastic strains were generally in the range $0 \cdot 3-1 \cdot 8 \%$ (Ref. 21 ) and linear stressstrain relations could approximate the work hardening rates. These rates evaluated to about 105 and $130 \mathrm{MPa}$ per percentage strain for the 3 and $4 \% \mathrm{Mn}$ furnace cooled specimens, rising to about 235 and $250 \mathrm{MPa}$ per percentage strain for the fast cooled alloys, respectively.

All apparent bend strengths of TRS specimens regardless of composition and processing parameters, were in the range $800-1260 \mathrm{MPa}$ for sponge iron alloys and 


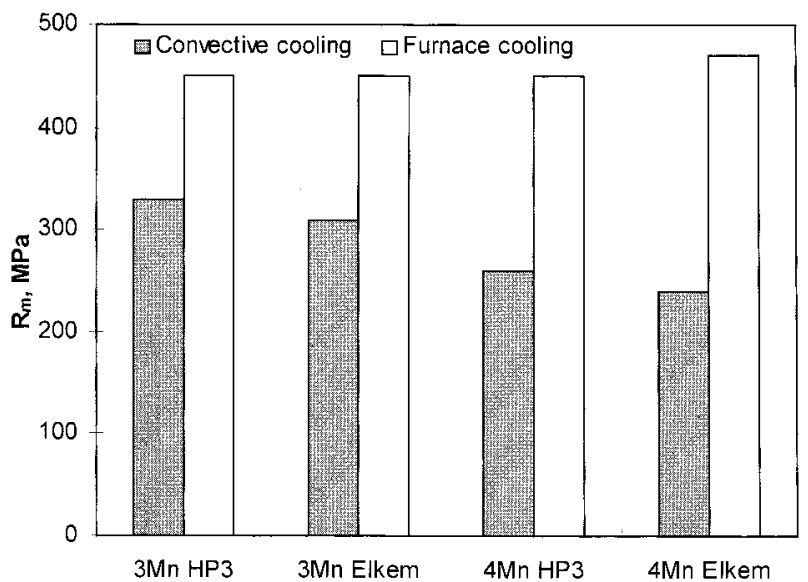

6 Histogram of mean tensile strengths of $3 \mathrm{Mn}-0 \cdot 8 \mathrm{C}$ and $4 \mathrm{Mn}-0.8 \mathrm{C}$ steels processed using HP3 and Elkem ferromanganese powders and cooled from sintering temperature of $1180^{\circ} \mathrm{C}$ at 3 and $40 \mathrm{~K} \mathrm{~min}^{-1}$ respectively: dewpoints were better than $-40^{\circ} \mathrm{C}$

640-1120 MPa for the water atomised alloys. The data for the rapidly cooled specimens are presented in Fig. 7 as Weibull plots, with $m$ values of about 6 , for both the 3 and $4 \% \mathrm{Mn}$ alloys. A systematic evaluation of these raw results will be attempted below, using the previously determined work hardening exponents to estimate the maximum tensile stresses at fracture.

\section{DISCUSSION}

The TRS values for similarly processed materials far exceed the TS values. Before the statistical size effect can be considered, account must be taken of the plastic deformation taking place in the outer layers of the bend specimens. The TRS formula (equation (1)) derives from the fundamental solid mechanics beam relationship

$$
\frac{M}{I}=\frac{\sigma}{y}=\frac{\sigma_{\max }}{(t / 2)}=\frac{E}{R}
$$

for linear elastic deformation to a radius $R$ by a force $F$ applied at midspan $l$. For simple (three point) bending, $M$ is the bending moment $(F l / 4), \sigma$ the stress at midspan at a distance $y$ from the neutral axis, and $\sigma_{\max }$ the stress in the outer fibre at midspan ( $t / 2$ from the neutral axis). For a rectangular beam of depth $t$, width $b$, with the second bending moment of area $M$ of $b t^{3} / 12$, equation (1) becomes

$$
\mathrm{TRS}=\sigma_{\max }=\frac{3 F l}{2 b t^{2}}
$$

Assuming that transverse sections which are plane before bending remain plane after elastic-plastic bending (Bernouilli-Euler) and that the stress-strain relation for the tested material is

$$
\sigma=\sigma_{\mathrm{Y}}+w E\left(\varepsilon-\varepsilon_{\mathrm{Y}}\right)=E \varepsilon_{\mathrm{Y}}+w E \varepsilon_{\mathrm{P}}
$$

where $\sigma_{\mathrm{Y}}$ is the yield stress and $w E$ the work hardening rate, then

$$
M=\int_{-\mathrm{t} / 2}^{+\mathrm{t} / 2} \sigma b y \mathrm{~d} y=2 \int_{0}^{\mathrm{t} / 2} \sigma b y \mathrm{~d} y
$$

The elastic beam formula can now be modified by inserting the relevant expressions for $M$. If the deformation for $0<y<h / 2$ is elastic and for $h / 2<y<t / 2$ is elastic-plastic

$$
M=2 \int_{0}^{\mathrm{h} / 2} E \varepsilon_{\mathrm{e}} b y \mathrm{~d} y+2 \int_{\mathrm{h} / 2}^{\mathrm{t} / 2}\left(E \varepsilon_{\mathrm{Y}}+w E \varepsilon_{\mathrm{P}}\right) b y \mathrm{~d} y
$$

If $\varepsilon_{\max }$ is the outer fibre strain at fracture, as $\varepsilon=2 \varepsilon_{\max } y / t$,

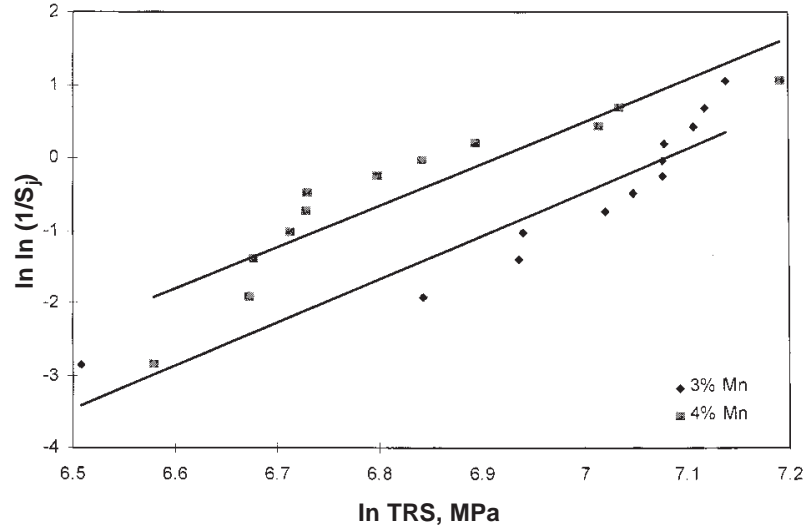

7 Weibull plots of apparent transverse rupture strengths (TRS) of steels processed together with tensile specimens of Fig. 6

$$
\begin{aligned}
& \text { i.e. } \varepsilon_{\max }=t \varepsilon / 2 \varepsilon y \text {, and } \mathrm{dy}=t \mathrm{~d} \varepsilon / 2 \varepsilon_{\max } \text {, therefore } \\
& \qquad \begin{aligned}
M= & 2 b E \int_{0}^{\mathrm{h} / 2} \varepsilon\left(\frac{t}{2 \varepsilon_{\max }}\right) \mathrm{d} \varepsilon+2 b E \\
& \times \int_{\mathrm{h} / 2}^{\mathrm{t} / 2}\left[\varepsilon_{\mathrm{Y}}+w\left(\varepsilon-\varepsilon_{\mathrm{Y}}\right)\right]\left(\frac{t \varepsilon}{2 \varepsilon_{\max }}\right)\left(\frac{t}{2 \varepsilon_{\max }}\right) \mathrm{d} \varepsilon
\end{aligned}
\end{aligned}
$$

i.e.

$$
\begin{aligned}
M= & 2 b\left(\frac{t}{2 \varepsilon_{\max }}\right)^{2} E \\
& \times\left\{\int_{0}^{\mathrm{h} / 2} \varepsilon^{2} \mathrm{~d} \varepsilon+\int_{\mathrm{h} / 2}^{\mathrm{t} / 2}\left[\varepsilon_{\mathrm{Y}}(1-w) \varepsilon+w \varepsilon^{2}\right] \mathrm{d} \varepsilon\right\}
\end{aligned}
$$

which evaluates to

$$
M=b\left(\frac{t}{2 \varepsilon_{\max }}\right)^{2} \frac{E}{3}\left[2 w \varepsilon_{\max }^{3}+(1-w) \varepsilon_{\mathrm{Y}}\left(3 \varepsilon_{\max }^{2}-\varepsilon_{\mathrm{Y}}^{2}\right)\right]
$$

or

$$
M=\frac{b t^{2} E}{12}\left\{2 w \varepsilon_{\max }+(1-w) \varepsilon_{\mathrm{Y}}\left[3-\left(\frac{\varepsilon_{\mathrm{Y}}}{\varepsilon_{\max }}\right)^{2}\right]\right\}
$$

As the bending moment, $M=F l / 4$ also equals $b t^{2}$ TRS $/ 6$, therefore

$$
2 \mathrm{TRS}=E\left\{2 w \varepsilon_{\max }+(1-w) \varepsilon_{\mathrm{Y}}\left[3-\left(\frac{\varepsilon_{\mathrm{Y}}}{\varepsilon_{\max }}\right)^{2}\right]\right\}
$$

Average values of mechanical properties determined in the tensile tests that were used in the calculations of maximum applied tensile stress in the bend tests for 3 and $4 \% \mathrm{Mn}$ alloys with Young's modulus of $115 \mathrm{GPa}$ each were $\sigma_{\mathrm{Y}}=350$ and $310 \mathrm{MPa}, \varepsilon_{\mathrm{Y}}=0 \cdot 30$ and $0 \cdot 27 \%$, and $w=0 \cdot 20$ and $0.22 \mathrm{~mm}$. For the bend specimens whose TRS values are plotted in Fig. $4, \varepsilon_{\mathrm{P}}$ and $\sigma_{\max }$ were evaluated and are presented in Table 1.

The derived values of $\sigma_{\max }$ were Weibull plotted (Fig. 8), giving $m$ values of 4.5 and 4.0 for the 3 and $4 \% \mathrm{Mn}$ alloys respectively, comparable with the TRS values (Fig. 7). It should be noted that, assuming the data obey the two parameter Weibull distribution (which is doubtful, especially for the $4 \% \mathrm{Mn}$ alloy) the probability of attaining $1 \mathrm{GPa}$ (and $2.5 \%$ strain) is 70 and $50 \%$ for the 3 and $4 \% \mathrm{Mn}$ alloys, respectively. The values of $\sigma_{\max }$, however, still exceed those of the strength of concurrently processed tensile specimens. Recalling equation (2), it is appropriate to consider whether this can be ascribed as a Weibull size (volume or area) and loading mode effect. It should be noted that this 'volume defects' relation (whose derivation involves triple integrals) is applicable to an elastically 


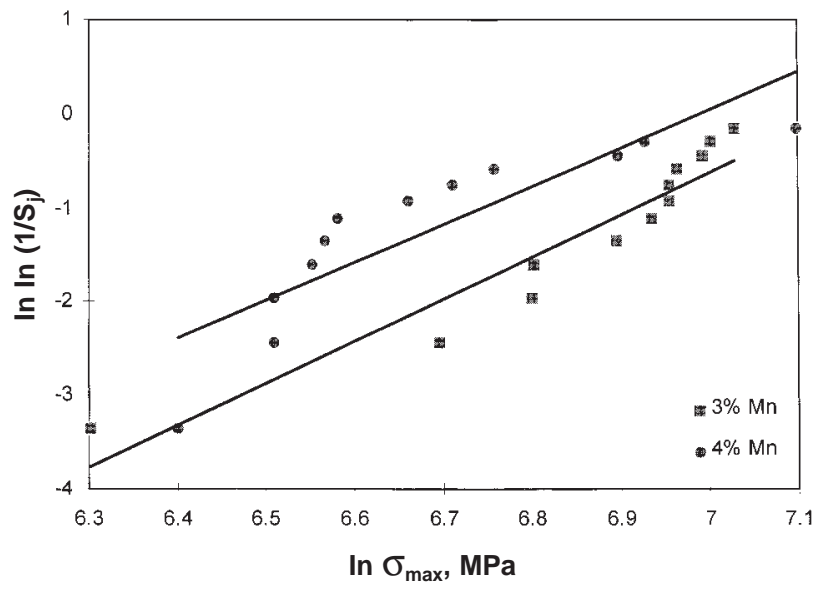

8 Weibull plots of maximum tensile stresses of steels determined in bending: $\sigma_{\max }$ calculation took account of prefailure plastic strains presented in Table 1

deforming beam $^{17}$

$$
\sigma_{\max } / \mathrm{TS}=\left[2 L W T(m+1)^{2} / l w t\right]^{1 / \mathrm{m}}
$$

The relevant dimensions for the tensile specimens were: gauge length $L, 10 \mathrm{~mm}$, width $W, 5.7 \mathrm{~mm}$, and thickness $T$, $6.2 \mathrm{~mm}$ and for the TRS specimens, width $w, 10.8 \mathrm{~mm}$, beam depth $t, 5.1 \mathrm{~mm}$, and span $l, 28.6 \mathrm{~mm}$. This estimates the ranges for $\sigma_{\max }$, normalised to TS, to be 310-630 and $330-660 \mathrm{MPa}$, for the 3 and $4 \% \mathrm{Mn}$ steels respectively to be compared with the directly recorded TS values in the range $300-600 \mathrm{MPa}$, as reported above.

If it is assumed that failures are surface initiated, only the surface tensile stress is relevant, and the Weibull surface defect scaling factor becomes ${ }^{17}$

$$
\sigma_{\max } / \mathrm{TS}=\left\{2 L(T+W)(m+1)^{2} / l[t+(m+1) w]\right\}^{1 / \mathrm{m}}
$$

which is generally about $20 \%$ smaller than that for volume defects for the present geometries. Taking into account the variability in the microstructure of the specimens, depending on the position in the furnace during the rapid cooling, the plasticity plus Weibull correlation is deemed to be satisfactory and a vindication of the analytical procedure adopted. A similar analysis was carried out for furnace cooled specimens. ${ }^{22}$ When carefully controlled processing was undertaken in one laboratory furnace for the $3 \mathrm{Mn}-0.6 \mathrm{C}$ alloy, TRS reproducibility was much higher and the 'true' bend strength data, showing an $m$ value of 16, are shown in Fig. 5. It is seen that careful processing of manganese alloys leads to highly consistent mechanical properties.

Powder metallurgy manganese steels have been most extensively researched by Salak; numerous references are included in his book on ferrous powder metallurgy, ${ }^{11}$ of which the outstanding contribution, in terms of mechanical properties, is Ref. 3. Salak et al. report there the attainment of this combination of properties for a $3 \cdot 5 \mathrm{Mn}-0.5 \mathrm{Mo}-0 \cdot 3 \mathrm{C}$ steel: $R_{\mathrm{m}} 690 \mathrm{MPa}, R_{\mathrm{mb}}$ (TRS) $1210 \mathrm{MPa}$, and $\mathrm{A}_{5}$ of $6 \cdot 2 \%$. Noteworthy in this alloy is the use of Hametag powder (now unavailable) and the presence of molybdenum. The shape of Hametag powder is leaflike and accordingly the very small diffusion paths for homogenisation are easily attainable. Alloying with molybdenum, as reported by Shivanath et al., ${ }^{7}$ is another example of the potential of manganese steels, once the problem of oxide networks is overcome.

\section{CONCLUSIONS}

1. $2-4 \% \mathrm{Mn}$ steels were sintered in dry, hydrogen rich atmospheres to yield predominantly pearlitic microstructures devoid of oxide networks.

2. Young's modulus determined by extensometric technique was about $115 \mathrm{GPa}$, and $153 \mathrm{GPa}$ by an ultrasonic method, in accord with the law of mixtures.

3. The majority of the experiments were conducted on 3 and $4 \mathrm{Mn}-0 \cdot 6 \mathrm{C}$ alloys and for these $R_{0 \cdot 1}$ was in the range 275-500 MPa, tensile strength (TS) 300-600 MPa, apparent transverse rupture strength (TRS) $640-1260 \mathrm{MPa}$, and plastic strains were up to $7 \%$.

4. Statistical techniques had to be employed to analyse the data. When careful control of processing was maintained, the Weibull modulus $m$ was highest for TS of furnace cooled specimens, at about 17 , and lowest, at about 6 , for TRS of rapidly cooled specimens.

5. By taking account of the plastic strains preceding failure, the elastic strength of materials formula was modified to allow true fracture stresses to be calculated. These were still smaller than TRSs.

6. It was postulated that failure was initiated from a population of flaws of variable size. When statistical account was taken of the magnitudes of the strained volumes and the distribution of stresses within them in the TS and TRS specimens, a Weibull analysis showed good correlations between normalised values of bend and the determined tensile strengths.

7. It is suggested that, as this two stage approach has a sound scientific basis, it should be employed to interpret bend test data in preference to empirical correlations between TRS and TS.

\section{ACKNOWLEDGEMENTS}

The present work formed part of a European Union cooperative programme with countries of Central and Eastern Europe, Copernicus, and was financed by contract CIPA CT-94-0108. The input of the partner bodies,

\begin{tabular}{|c|c|c|c|c|c|c|c|}
\hline \multicolumn{4}{|l|}{$3 \% \mathrm{Mn}$ steel } & \multicolumn{4}{|l|}{$4 \% \mathrm{Mn}$ steel } \\
\hline TRS, MPa & $\varepsilon, \%$ & $\varepsilon_{\mathrm{P}}, \%$ & $\sigma_{\max }, \mathrm{MPa}$ & TRS, MPa & $\varepsilon, \%$ & $\varepsilon_{\mathrm{P}}, \%$ & $\sigma_{\max }, \mathrm{MPa}$ \\
\hline 670 & $1 \cdot 15$ & $0 \cdot 85$ & 550 & 720 & $1 \cdot 42$ & $1 \cdot 16$ & 600 \\
\hline 940 & $2 \cdot 30$ & $2 \cdot 00$ & 810 & 790 & $1 \cdot 70$ & 1.43 & 670 \\
\hline 1030 & 2.69 & $2 \cdot 39$ & 900 & 790 & $1 \cdot 70$ & $1 \cdot 43$ & 670 \\
\hline 1030 & 2.69 & $2 \cdot 39$ & 900 & 820 & $1 \cdot 82$ & $1 \cdot 55$ & 700 \\
\hline 1120 & 3.08 & $2 \cdot 78$ & 990 & 830 & $1 \cdot 86$ & $1 \cdot 58$ & 710 \\
\hline 1160 & $3 \cdot 25$ & $2 \cdot 95$ & 1030 & 840 & 1.90 & 1.62 & 720 \\
\hline 1180 & $3 \cdot 34$ & $3 \cdot 04$ & 1050 & 900 & $2 \cdot 13$ & $1 \cdot 86$ & 780 \\
\hline 1180 & $3 \cdot 34$ & 3.04 & 1050 & 940 & $2 \cdot 29$ & $2 \cdot 02$ & 820 \\
\hline 1190 & $3 \cdot 38$ & $3 \cdot 08$ & 1060 & 980 & $2 \cdot 44$ & $2 \cdot 17$ & 860 \\
\hline 1220 & $3 \cdot 51$ & $3 \cdot 21$ & 1090 & 1110 & $2 \cdot 96$ & $2 \cdot 69$ & 990 \\
\hline 1230 & 3.55 & $3 \cdot 25$ & 1100 & 1140 & $3 \cdot 07$ & $2 \cdot 80$ & 1020 \\
\hline 1260 & 3.68 & $3 \cdot 38$ & 1130 & 1330 & $3 \cdot 82$ & $3 \cdot 55$ & 1210 \\
\hline
\end{tabular}

Table 1 Estimates of maximum stresses in beams of 3 and $4 \% \mathrm{Mn}$ alloys undergoing simple elastic-plastic bending 
Institute of Metals Science (Sofia, Bulgaria), Trzebinia Metallurgical Works (Poland), Miskolc University (Hungary), and Ecole Centrale de Lyon (France), is also acknowledged.

\section{REFERENCES}

1. EU Carcinogen Directives 90/394/EEC and 91/322/EEC.

2. A. SALAK: Powder Metall. Int., 1980, 2, 72-75.

3. A. SAlak, E. DUdrova, and v. Miskovic: Powder Metall. Sci. Technol., 1992, 3, 26-35.

4. I. M. V. CANINHA and F. C. RISSO ASSUNCAO: PM '90: World Congress on Powder Metallurgy, Vol. 3, 94; 1990, London, The Institute of Metals.

5. G. H. DANNINGER, R. POTTSCHANCHER, G. JANGG, J. SEYRKAMMER, and A. SALAK: PM '94: World Congress on Powder Metallurgy, Vol. 2, 879; 1994, Les Ulis, Les Editions de Physique.

6. A. N. KLEIN, R. OBERACKER, and F. THUMMLER: Powder Metall. Int., 1985, 17, 13-16, 71-74.

7. R. SHIVANATH, P. K. JONES, and R. LAWCOCK: 'Advances in powder metallurgy and particulate materials', 413-427; 1996, Princeton, NJ, MPIF.

8. A. S. WRONSKI et al: Final report on EU Copernicus contract CIPA CT-94-0108, European Commission, Brussels, Belgium, 1998.

9. J. R. MOON: 'Deformation and fracture in structural materials', (ed. L. Parilak et al.), Vol. 1, 61; 1996, SAS Kosice.

10. L. F. PEASE III: PM '92: World Congress on Powder Metallurgy, 151; 1992, Princeton, NJ, MPIF.
11. A. SALAK: 'Ferrous powder metallurgy', 342; 1995, Cambridge, Cambridge Interscience Publishing.

12. P. W. SHELTON and A. S. WRONSKI: in 'Towards improved performance of tool materials', (ed. R. S. Irani), 176; 1982, London, The Metals Society.

13. G. STRAFFELINI, V. FONTANARI, A. MOLINARI, and L. BERTINI: 'Advances in powder metallurgy and particulate materials', 13-70; 1996, Princeton, NJ, MPIF.

14. W. WeIBULl: Trans. R. Inst. Technol., 1949, 47.

15. R. D. QUINN and R. MORRell: J. Am. Ceram. Soc., 1991, 74, 2037.

16. R. DANZER, J. PROB, H. SCHUBERT, and G. PETZOW: PM '90: World Congress on Powder Metallurgy, Vol. 2, 118; 1990, London, The Institute of Metals.

17. A. S. WRONSKI, M. GOMES, Y. BIENVENU, and L. FONTAINE: Proc. PM '94: World Congress on Powder Metallurgy, Vol. 2, 1053; 1994, Les Ulis, Les Editions de Physique.

18. D. J. SCHAEFFLER, A. LAWLEY, and R. J. CAUSTON: PM '92: World Congress on Powder Metallurgy, 93; 1992, Princeton, NJ, MPIF.

19. T. PIECZONKA, S. C. MITCHELl, A. CIAS, M. SULOWSKI, and A. S. WRONSKI: Inz. Materialowa, 1998, 4, 1171-1174.

20. R. HAYNES: in 'Reviews of deformation behaviour of materials' 9-101; 1997, London, Freund Publishing House.

21. R. HAYNes: Powder Metall., 1977, 20, 17-20.

22. A. CIAS, S. C. MITCHELl, and A. S. WRONSKI: PM '98: World Congress on Powder Metallurgy, Vol. 3, 179-184; 1998, Shrewsbury, EPMA.

\begin{tabular}{|c|}
\hline 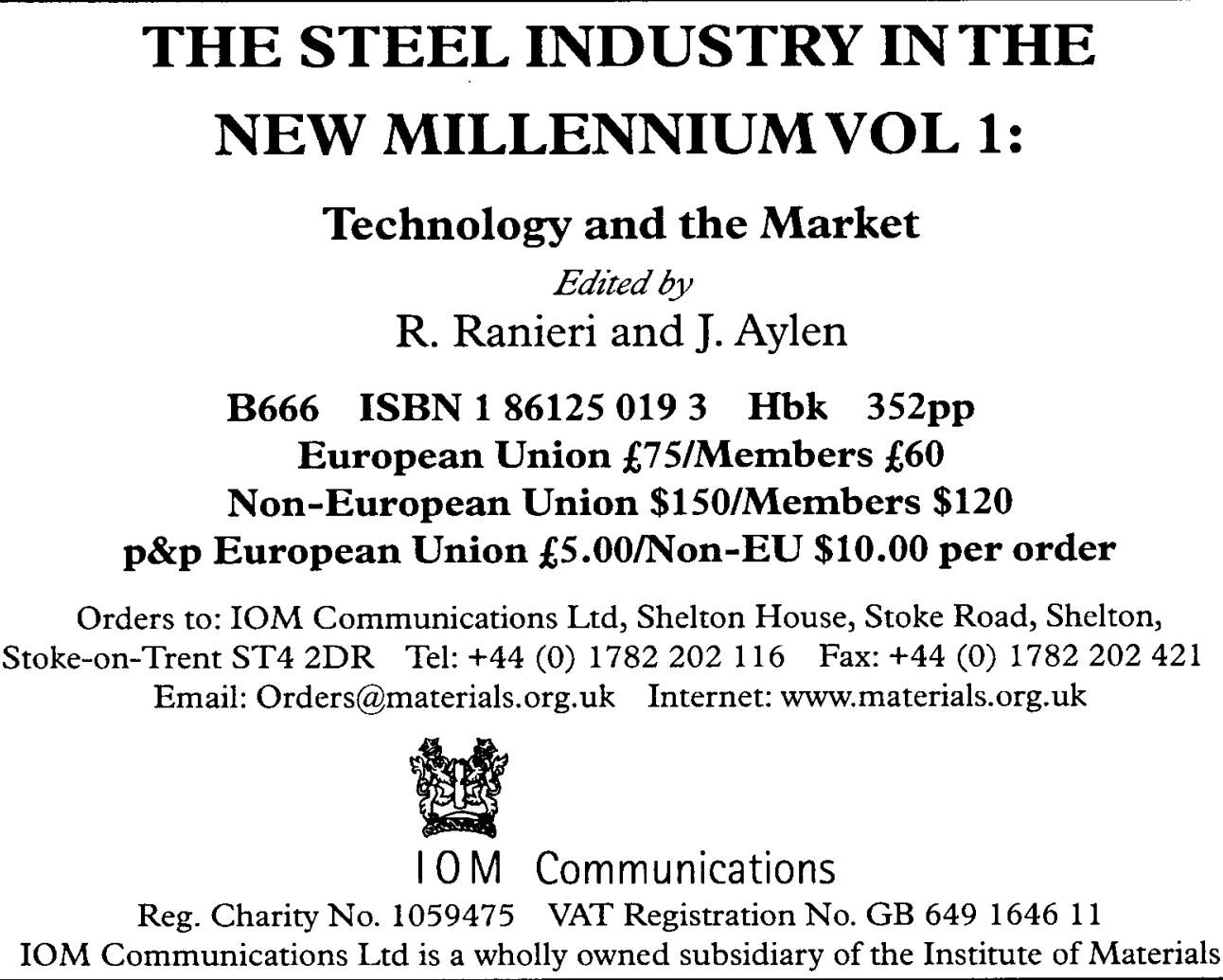 \\
\hline
\end{tabular}

